\title{
The Effects of Standard and Reversed Code Mixing on L2 Vocabulary Recognition and Recall
}

\author{
Abbas Ali Zarei (Corresponding author) \\ Tel: 00989122818077 \\ Paria Zarnani, M.A \\ Islamic Azad University, Takestan, Iran
}

Assistant professor, Imam Khomeini International University, Qazvin, Iran

E-mail: aazarei@ikiu.ac.ir

Received: 12-06- 2012

Accepted: 25-07- 2012

Published: 01-09- 2012

doi:10.7575/ijalel.v.1n.4p.183

URL: http://dx.doi.org/10.7575/ijalel.v.1n.4p.183

\begin{abstract}
To investigate the effects of two code mixing conventions on L2 vocabulary recognition and recall, 87 female Iranian lower intermediate EFL learners were divided into three groups. One group received vocabulary instruction through standard code mixing in which an L1 lexical item was incorporated within an L2 context; another received the same instruction through reversed code mixing, which involved the use of an L2 lexical item within an L1 context. The third group was a comparison group that was presented with the same words in English sentences without any code mixing. At the end of the treatment, multiple-choice and fill-in-the-blanks vocabulary tests were administered to all three groups. The gathered data were analyzed using two separate one-way ANOVA procedures. Results indicated that code mixing conventions had no significant effect on the learners' vocabulary recognition. As to vocabulary production, the comparison group outperformed the standard code mixing group in a statistically significant way. The findings of the present study may have implications for learners, teachers, and syllabus designers.
\end{abstract}

Keywords: code mixing - vocabulary recognition - vocabulary production - standard code mixing - reversed code mixing

\section{Introduction}

Vocabulary learning is one of the most important areas of applied linguistics and second language acquisition. It is commonly believed that learning vocabulary is fundamental, important, but difficult (Shen, 2003). When learners encounter a new vocabulary item for the first time, they may guess the meaning and usage from clues, or they may look up the word in a dictionary. Some might take down notes along the margins, between the lines, or on separate vocabulary notebooks. Others may simply resort to their mother tongue.

One of the little- known factors that might influence L2 vocabulary learning, and is related to the use of mother tongue, is code mixing. According to Celik (2003), code mixing is the mixture of native and target languages which generally includes one word or phrase from one language in the syntax of another. The following examples show personal observations concerning the notion of code mixing with Persian and English.

1. I am sure that practice will improve your sعد

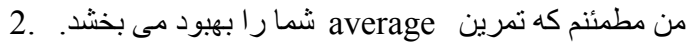

3. ( I am sure that practice will improve your average.)

As the above examples show, code mixing may generally appear in two forms. In the first variety, which is more or less the standard practice and is referred to as standard code mixing here, an L1 lexical item is incorporated within an L2 context. Conversely, reversed code mixing, as it is referred to here, includes the use of an L2 lexical item within an L1 context (example 2).

Little is known about the exact nature of the effect of such mixtures on L2 vocabulary learning. In an attempt to fill this gap, the present study aims to address the following questions: 
International Journal of Applied Linguistics \& English Literature

ISSN 2200-3592 (Print), ISSN 2200-3452 (Online)

Vol. 1 No. 4; September 2012

1- Are there any significant differences among the effects of code mixing conventions on vocabulary recognition?

2- Are there any significant differences among the effects of code mixing conventions on vocabulary production?

\section{Literature Review and Theoretical Framework}

Meeting unfamiliar vocabulary is among the apparent and unavoidable challenges faced by language learners (Newton, 2001). Most second language readers emphasize that their main obstacle to reading is lack of enough vocabulary knowledge (Alessi \& Dwyer, 2008). On the other hand, according to Read (2004), even teachers are not usually certain about how best to integrate vocabulary into their teaching. The importance of vocabulary knowledge coupled with such uncertainties surrounding the way(s) to present it warrant more studies in this area.

In an attempt to shed some light on L2 vocabulary learning processes, Midgley, Holcomb, and Grainger (2009) refer to the mechanisms involved in word recognition in second and foreign language learning, and the extent to which they overlap with the mechanisms underlying word recognition in the first language. One option is that the mechanisms are mostly the same, and L2 words are integrated into a common set of lexical representations much like recently obtained words in L1. For some reason, this would appear to be an improbable option for late learners of a second language, at least in the early phases of L2 acquisition. First, many L2 learners use translation into L1 for processing L2 words. Second, due to the relatively large number of cognates in languages such as English and French, establishing L2-L1 form-form associations would be more economical than creating new form-meaning associations (Midgley, Holcomb, \& Grainger, 2009, p. 282).

Brooks-Lewis (2009) holds that learners' perceptions of their experience with integration of their L1 in learning a foreign language are remarkably positive; for this reason, adult learners feel that the inclusion of their L1 in the classroom makes the learning process both meaningful and pleasurable.

Moreover, recent discussions regarding the use of L1 in the foreign language classroom are indicative of the need for a change in approach, linking the use of L1 to issues of language acquisition (Liebscher \& Dailey-O'Cain, 2005). Similarly, Butler and Gutierrez (2003) point out that language mixing activities were perceived as evidence of bilinguals' linguistic incompetence until the 1970s, and that today there may be no justification for excluding L1 from L2 learning contexts. They also state that much research has concentrated on syntactic and pragmatic features of language mixing, as well as its societal meaning. This somehow implies that there is insufficient research on the application of L1 to the learning of L2 vocabulary.

One area that deserves greater attention in this respect is code mixing. The term code mixing has been defined using different terminologies. According to Ayeomoni (2006), code mixing is the embedding of different linguistic parts, for instance affixes, words, phrases and clauses from a co-operative activity where the participants, in order to conclude what is intended, must merge what they hear with what they understand. Looking at code mixing from a different perspective, Yee Ho (2007) defines it as the transform of one language to another within the same statement or in the same verbal/written text. In much the same way, according to Fasold (1984), in code mixed sentences, a speaker basically uses pieces of one language while using another language.

There are various classifications of code mixing. According to Martin (1999) and Pagett (2006), a distinction is sometimes made between 'code switching' and 'code mixing'. The former relates to language switches at sentence boundaries ('inter-sentential switching'), whereas the latter refers to switching or mixing languages within a sentence ('intra-sentential switching').

Jisa (2000) asserts that inter-sentential code switching engages the use of sentential constituents from two languages in the same discourse. Each sentential constituent follows the grammar of its respective language. Intra-sentential switching happens within the confines of a single sentence or clause constituent.

On the other hand, the terms 'inter-sentential' and 'intra-sentential' code mixing are regarded by Sharp (2007) as descriptively unsatisfactory when working with spoken discourse on grounds that it is hard to determine where one sentence ends and another begins. He uses the terms 'mixed' and 'unmixed' utterances to explain the resultant entities of an integration of two languages.

The models of intra-sentential code mixing (the focus of this study) are often rather different from one another (Muysken, 2000). They include the following:

- Insertion of material ( lexical items or entire constituents) from one language into a structure from the other language

- Alternation between structures from languages 
International Journal of Applied Linguistics \& English Literature

ISSN 2200-3592 (Print), ISSN 2200-3452 (Online)

Vol. 1 No. 4; September 2012

- Congruent lexicalization of material from different lexical inventories into a shared grammatical structure (p.3).

Muysken states that in the insertion pattern in general, the overall structure is determined by the language into which components of the other language are inserted. Here the process of code mixing is considered as something similar to borrowing: the insertion of a foreign lexical or phrasal category into a given structure. The difference would simply be the size and type of the element inserted, e.g. noun against noun phrase.

Deuchar (2005) holds that in the alternation pattern, both languages, each with its own structure, occur alternatively. In other words, a true switch from one language to the other takes place which involves both grammar and lexicon (Muysken, ibid).

In the third type of code mixing, congruent lexicalization, "the grammatical structure is shared by languages $\mathrm{A}$ and $\mathrm{B}$, and words from both languages $\mathrm{a}$ and $\mathrm{b}$ are inserted more or less randomly" (Muysken, ibid, p.8). In the case of congruent lexicalization, it seems that there is mostly (but not necessarily completely) shared structure, lexicalized by elements from either language. The present study adopts the "insertion" model of code mixing in which only lexical items from one language are inserted into the structure of another.

The literature on the usefulness of code mixing is rather controversial. While some teachers see it as a sign of negative transfer from the mother tongue in the process of second language learning, others are less pessimistic and readily acknowledge its merits. Some researchers even see it as an integral, indispensible aspect of learning. For instance, while Shameem (2007) explains that code mixing has been considered negatively in the past by classroom teachers who saw its use as language error or regression in English language acquisition instead of a proof of multilingual competence, Muysken (1987) notes that code mixing is not a separate phenomenon, but a fundamental part of bilingual discourse, a feature of a fluent bilingual.

One of the main profits of code mixing, according to Celik (2003), is time; neither applying nor preparing this technique takes much time. He argues that another benefit of code mixing is that it does not need additional materials. For example a simple story is sufficient enough to introduce the target vocabulary.

May (2007) asserts that teachers rarely think about the real mechanism of inserting L2 into an L1 context. The supposition of code purity enables teachers to proceed with the accepted wisdom that this is the only effective way to learn a language. He also mentions that in contrast to teacher attitudes, linguistic and anthropological studies of code mixing show it to be a comprehensively incorporated and patterned feature of successful bilingual speech behavior.

In short, not only is it impractical to eliminate the L1 from the classroom but also it is probable to deprive learners of an important tool for language learning. In addition, many teachers have tried to create English-only classrooms, but have failed to get the meaning across; results have usually been incomprehension and resentment on the part of students (Harbord, 1992).

Judit (2000) holds that monolinguals are probable to be very critical of code mixing. They may even use negative, critical terms to describe the perceived results of mixing two languages, e.g. 'Franglais' (French and English in Quebec), 'Hunglish' (Hungarian and English). Perhaps due to this kind of criticism, many bilingual people come to be very self-conscious about their language change and try to stay away from it in talking to strangers or on formal occasions. To Judit, such dismissal of the phenomenon reveals serious misunderstanding.

Nonetheless, Muysken (1987) points out that mixing of two languages arbitrarily is impossible. He acknowledges that the procedure is subject to linguistic constraints, and several researchers have tried to find out what these constraints are. The most important debate in the study of syntactic constraint is whether code mixing is linear or structural in nature. In linear constraints, mixing is allowed when the orders of both languages are considered. Structural constraints allow mixing when structural coherence of both languages is considered.

According to Bing (1988), the most complete work on syntactic constraints on code mixing comes from Poplack (1980), who suggests two main restrictions in code switching, namely: the equivalence constraint and the free morpheme constraint. Lance (1975) suggests that possibly there are no syntactic constraints on where the switching can take place. However, more recent work on code alternation recommends that actually there are syntactic constraints on code mixing. In other words, code mixing can only take place when the syntactic construction is common to both languages. If the structure is unique to only one language, code mixing will not take place. 
Mahootian (1996) compares two schools of thought with regard to intra-sentential code switches; one position, like the above paragraph, offers universal structural constraints on intra-sentential code switching, whereas the other denies the possibility of such constraints being motivated only by syntactic considerations. She then proposes her own account of code mixing that does not resort to constraints specific to code mixing. She claims that the same principles and rules that govern the production of monolingual utterances apply in the production of code mixed utterances.

There is a paucity of research on the effect of code mixing on vocabulary learning. Some of the more relevant studies include the following:

Dussias (2002) used an extracted oral production task to find out whether comprehension preferences in code mixing could be repeated by using experimental production data. Two sentence parts, one in Spanish and one in English, were shown on a computer screen, one below the other. Participants were trained to read both phrases aloud and to produce a complete sentence by combining the two phrases using only one word, either from English or from Spanish. The results suggested that linguistic, psycholinguistic and discourse principles may influence the frequency patterns visible in spontaneous discourse for code mixed utterances.

Dussias (2003) reports the findings of a study by Wakefield, Bradley, Lee Yom, and Doughtie (1975) which used reaction-time data to investigate code mixing. They timed participants' responses to sentences that differed systematically with regard to the site of an intra-sentential switch. Results showed that the time to respond to a true-false question related to the stimuli that participants heard was mainly longer when the switch did not happen at a definable syntactic boundary.

In a study carried out by Celik (2003), the teacher introduced the story or topic and explained it by inserting the new (target, vocabulary in L1). Then, in an oral task, students were asked to form pairs to discuss the topic just introduced, with no instruction as to the use of the newly introduced words. As the participants started to discuss the topic, he observed that most of the students used many of the target words. Celik also had the students write down what they had discussed. One of the remarkable features of the participants' written output was that they never used L1 lexical items in spite of the fact that they encountered difficulties with spelling, syntax and usage. Regarding the use of new vocabulary, some students hardly referred to the points raised in the listening. When they did, however, they had a tendency to paraphrase the concepts instead of producing near-synonyms.

There is almost a dearth of research as to the effect of code mixing on EFL vocabulary learning. In an attempt to partially fill this gap, the present study aims to investigate the effects of standard and reversed code mixing conventions on receptive and productive vocabulary learning.

\section{Method}

\subsection{Participants}

The participants of the present study were 87 female Iranian lower intermediate EFL learners with an average of 4 to 5 years of previous English study at high school in Gheidar (Zanjan Province, Iran). They were in three groups. Each group of participants was randomly assigned to a different treatment condition to receive vocabulary instruction through standard code mixing, reversed code mixing and English sentences.

\subsection{Materials and Instruments}

To homogenize the participants in terms of vocabulary knowledge, the vocabulary subtest of a Key English Test (KET) was administered. The test had thirty five items in multiple choice format. To ensure that the participants had no prior knowledge of the target words, a vocabulary pretest was also given which included 75 target words from high school books. In addition, to measure the participants' receptive and productive knowledge of words after the treatment, two posttests, a receptive and a productive word knowledge tests were also administered. To measure the participants' vocabulary recognition, a 30-item multiple-choice achievement test was constructed and administered in which the participants were required to recognize the alternative that most appropriately completed each sentence. Another 30-item achievement test in fill-in-the blanks format was given which required the participants to produce the target words to complete the given sentences. To prevent the possibility of learners providing near synonyms, the initial letter of the target words was also given.

\subsection{Procedures}

Initially, a sample of 112 Iranian lower intermediate-level EFL learners with the afore-mentioned characteristics was selected. A standard vocabulary subtest of Key English Test was administered to homogenize the participants in terms of their vocabulary knowledge. The mean and standard deviation of the participants' scores were then 
computed, and those whose score was more than half a standard deviation away from (either above or below) the mean were excluded from all subsequent analyses. As a result, there remained 87 learners who acted as the participants of the study. Furthermore, to minimize the effect of the participants' prior knowledge of the target words, the pretest, including 75 items, was administered. The participants were given the seventy five words in context and were required to write the L1 translation of each word. As a result, seven words to which the participants had responded correctly were eliminated, and the remaining 68 words were chosen to be presented to the three groups. Those words of which students had prior knowledge were also eliminated from the posttests. Then, the treatment began, which lasted over 11 sessions. The participants were in three groups. Each group was randomly assigned to one of the treatment conditions: The first group acted as the comparison group and received vocabulary items in English sentences (e.g., I have an appointment with the dentist). The members of the second group (standard code mixing group) were presented with English sentences in each of which one of the target

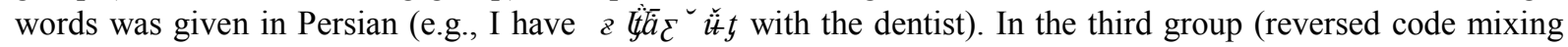
group), the participants were presented with Persian sentences in each of which a target word was given in English (e.g., با دندانيزُشك دارم). In each session, six words were presented.

At the end of the instructional period, the participants' receptive vocabulary knowledge was tested through a multiple-choice test and their productive vocabulary knowledge was measured through a fill-in-the-blanks test. The gathered data were then analyzed through two separate one-way ANOVA procedures; one of the procedures was used to investigate the effectiveness of code mixing convections on vocabulary recognition and the other was utilized to compare the scores of the three groups on the vocabulary production test. It needs to be noted that both posttests were presumed to be content valid because they were both achievement tests and were constructed based on the materials taught. The reliability index of the post tests was estimated using the KR-21 formula, based on which the reliability index of the receptive and productive tests turned out to be 0.86 and 0.82 , respectively.

\section{Results}

The first research question sought to investigate which type of code mixing is more conducive to learners' vocabulary recognition. To this end, a one-way ANOVA procedure was used. Descriptive statistics and the ANOVA results on vocabulary recognition are summarized in Table 1.

Table 1. The descriptive statistics and ANOVA results on vocabulary recognition

\begin{tabular}{lccc}
\hline \multicolumn{1}{c}{ Method } & N & Mean & Std. Deviation \\
\hline No code mixing & 29 & 22.86 & 4.87 \\
Standard code mixing & 30 & 22.20 & 6.49 \\
Reversed code mixing & 28 & 19.60 & 6.37 \\
\hline \multicolumn{3}{c}{ F $=2.36$} & Sig. 0.10 \\
\hline
\end{tabular}

Based on Table 1, it is evident that the comparison group has the highest mean, followed closely by the standard code mixing group. The reversed code mixing group has the lowest mean. Moreover, since the F value of 2.36 is not statistically significant $(\mathrm{P}>.05)$, it can be concluded that there are no statistically significant differences among the three groups. This means that code mixing conventions do not have a significant effect on the learners' vocabulary recognition.

The second research question aimed to see which of the treatment conditions yields better results in improving learners' productive knowledge. Descriptive and test statistics are given in Table 2.

Table 2. The descriptive and test statistics for the ANOVA on vocabulary production

\begin{tabular}{lccc}
\hline Method & N & Mean & Std. Deviation \\
\hline No code mixing & 29 & 24.51 & 3.68 \\
Standard code mixing & 30 & 20.70 & 5.86 \\
Reversed code mixing & 28 & 23.46 & 5.07 \\
\hline \multicolumn{1}{c}{ F $=4.98$} & & & Sig. $=.009$
\end{tabular}


Based on Table 2, it is evident that the comparison group has the best performance followed by the reversed code mixing group. The standard code mixing group has the lowest mean. As Table 2 shows, the differences among the three groups are statistically significant $(\mathrm{F}=4.98, \mathrm{P}>.05)$. That is, different types of code mixing yield different results in improving learners' productive knowledge. To locate the differences between the means, a post-hoc Scheffe' test was used. The results appear in Table 3.

Table 3. Multiple Comparisons of Means for the Learners' production ANOVA

\begin{tabular}{ccccc}
\hline convention & convention & $\begin{array}{c}\text { Mean } \\
\text { Difference }\end{array}$ & $\begin{array}{c}\text { Std. } \\
\text { Error }\end{array}$ & Sig. \\
& & & & \\
\hline No code mixing & Standard code mixing & $3.81^{*}$ & 1.29 & .01 \\
No code mixing & Reversed code mixing & 1.05 & 1.31 & .72 \\
Standard code mixing & Reversed code mixing & -2.76 & 1.30 & .11 \\
\hline
\end{tabular}

*. The mean difference is significant at the 0.05 level.

Table 3 shows that only the difference between the comparison and standard code mixing groups is statistically significant.

\section{Discussion and conclusion}

The results of the present study show that there are no significant differences among the three groups on the vocabulary recognition test. Unlike the findings of Hsu (2000, cited in Chen, 2006), which suggest that switching to other languages draws the attention of readers and helps them in understanding and recognizing words' meaning, this study shows that the performance of the comparison group was better. In addition, these findings fail to support Judit's (2000) assertion that code mixing can positively influence learning and that attempts at creating purely monolingual classes reveal grave misunderstandings. On the contrary, the result of the participants' performance on the vocabulary recognition test partially corroborates the concern voiced by Shameem (2007) that code mixing may actually be viewed as a regression in the process of second language learning. Although the differences among the means were not statistically significant, the means of both of the experimental groups were actually lower than that of the comparison group. One possible explanation for the obtained result might have been the possible conflict between the ways contextual clues were presented in the two languages. It might be that each of the native and target languages had its own system of contextual clues, and presumably a different way of presenting such clues. Since learners have to draw upon both their native and target language knowledge during code mixing, possible differences between the two languages in the way they provide contextual clues might lead to confusion and negatively affect the learning process.

Another interesting finding pertaining to the first research question is that the performance of the reversed code mixing group was comparatively worse than that of the standard code mixing group, though the difference was not statistically significant. This might be explained on grounds that the participants of the standard code mixing group had access to the contextual features of the target language, whereas the participants of the reversed code mixing group were provided only with native language contexts. Since some of the target words to be learnt may not lend themselves easily to comprehension in a foreign language context, the better performance of the standard code mixing group is not totally unexpected.

As to the production test, the first group of participants who received no code mixing performed significantly better the standard code mixing group. There was no significant difference between the standard and reversed code mixing groups, nor was there any significant difference between the reversed code mixing and the comparison groups. One possible reason for the better performance of the comparison group compared to the standard code mixing group may be that the members of the standard code mixing group practiced only with the Persian equivalents of the target words. This means that they might have developed some understanding of the general meaning of the word. But since they did not have much exposure to the target words in L2, they may not have developed productive knowledge of the words. Even if they knew the equivalent of the words they were exposed to in their L1, there might have been problems with areas such as spelling, which could have negatively affected their production. This might also explain why, unlike vocabulary recognition, where the standard code mixing group participants performed relatively better than their counterparts in the reversed code mixing group, Page | 188 
the opposite turned out to be true here. In fact, previous studies (such as Celik, 2003), have shown that one probable problem while teaching through standard code mixing involves learners' production of the target vocabulary. Teaching vocabulary via standard code mixing may lead learners to inaccurate spelling. The reason for this may be self-evident. Since learners do not see the target word, they do not develop any productive knowledge of it. In reversed code mixing, on the other hand, learners not only see the target word but also develop partial knowledge of how it functions based on the native language context.

The findings of the present study can have theoretical and practical implications for teachers, syllabus designers, and language testers. A clear understanding of how code mixing conventions can influence vocabulary recognition and production can help resolve the theoretical controversies surrounding the issue. In addition, such an understanding may influence the way syllabus designers prepare textbooks and help teachers make more informed decisions as to how to present lexical items to bring about the best result. Language testers might also employ their understanding of the nature of code mixing and its effect on vocabulary learning to influence teachers' teaching practices.

All the above, of course, require that a clear understanding of the nature of code mixing conventions and the way they might affect vocabulary learning be developed first. The findings of the present study are far from being capable of creating such an understanding. In fact, the controversial findings of the previous studies and the areas of conflict between the findings of the present study and those of previous studies are only indicative of a need for further research in this little explored area.

\section{References}

Alessi, S. \& Dwyer, A. (2008). Vocabulary assistance before and during reading. Reading in a Foreign Language, 20 (2), 246-263.

Ayeomoni, M. O. (2006). Code switching and code mixing: Style of language use in childhood in Yortuba speech community. Nordic journal of AfricanStudies, 15 (1), 90-99

Bing, Y. L. (1988). Constraints on intra-sentential code mixing in Cantonese and English. Linguistics and Language Teaching: Hong Kong: University of Hong Kong, 23-40.

Butler, G. Y. \& Gutierrez, B. M. (2003). Learning climates for English language learners: A case of fourth-grade students in California. Bilingual Research Journal, 24, 171-194.

Brooks-Lewis, K. A. (2009). Adult learners' perceptions of the incorporation of their L1 in foreign language teaching and learning. Applied Linguistics, 30 (2), 216-235

Celik, M. (2003). Teaching vocabulary through code mixing. ELT Journal, 59(4),361-369

Chen, C. W. (2006). The mixing of English in magazine advertisements in Taiwan.World Englishes, 25 (3/4), $467-478$

Deuchar, M. (2005). Minitory language survival: code mixing in welsh. Somerville, MA: Casacadilla Press.

Dussias, E. P. (2002). On the relationship between comprehension and production data in code switching. Amsterdam: John Benjamins, 27-38.

Dussias, E. P. (2003).Spanish-English code mixing at the auxiliary phrase: Evidence from eye-movement data. Pennsylvania state university.

Fasold, R. (1984). The Sociolinguistics of Society. Basil: Blackwell.

Harbord, J. (1992). The use of the mother tongue in the classroom. ELT Journal, 46 (4), 350-355.

Jisa, H. (2000). Language mixing in the weak language: Evidence from two children. Journal of Pragmatics, 32, 1363-1386.

Judit, O. (2000). A case study on the processes of code switching and code mixing in the speech of Hungarian Canadians. Hungarian electronic library. RetrievedSeptemer 17, 2009, from http://mek.niif.hu/02100/02124/pdf.

Lance, D.M. (1975). ' Spanish-English code-switching'. In El Lengua De Los Chicanos, edited by E. Hernandez-Chavez, Cohen \& Beltramo, pp. 138-153. Centre for Applied Linguistics, Arlington, Virginia.

Liebscher, G. \& O'cain, J. D. (2005). Learner code switching in the content-based foreign language classroom. Modern Language Journal, 89,234-247. 
International Journal of Applied Linguistics \& English Literature

ISSN 2200-3592 (Print), ISSN 2200-3452 (Online)

Vol. 1 No. 4; September 2012

Mahootian, S. (1996). Code switching and universal constraints: evidence from Farsi? English. World Englishes, 15 (3), 377-384.

Martin, P. W. (1999). Close encounters of a bilingual kind: interaction practices in the primary classroom in Brunei. International Journal of Educational Development, 19, 127-140.

May, T. (2007). Fractional language learning. Asian EFL Journal, 9 (4), 189-205.

Midgley, K. J.\& Holocomb, P. J.\& Grainger, J. (2009). Language effects in second

language learners and proficient bilinguals investigated with event-related potentials. Journal of Neurilinguistics, 22. 281-300.

Muysken, P. (1987). Neutrality in code mixing . Retrived August 3, 2009, from www.

repository.ubn.ru.nl/bitstream/206b/14621/1/3921.pdf

Muysken, P. (2000). Bilingual speech: a typology of code mixing. Cambridge: Cambridge university press.

Newton, J. (2001). Options for vocabulary learning through communication tasks. ELT Journal, 55 (1), 30-37.

Pagett, L.(2006). Mum and dad prefer me to speak Bengali at home: code switching and parallel speech in a primary school setting. Literacy, 40 (3). 137-145.

Poplack, S. (1980). Sometimes I'll start a sentence in Spanish y termino en espanol:toward a typology of code switching. Linguistics, 18,581-618.

Read, J. (2004). Research in teaching vocabulary. Annual Review of Applied Linguistics, 24, 146-161.

Shameem, N. (2007). Language education needs for multilingualism in Fiji primary schools. International Journal of Educational Development, 27, 39-60.

Sharp, H. (2007). Swedish-English language mixing. World Englishes, 26 (2), 224-240.

Shen W. W. (2003). Current trends of vocabulary teaching and learning strategies for EFL settings. Feng chia Journal of Humanities and Social Science, 7, 187-224.

Yee Ho, J. w. (2007). Code mixing: Linguistics form and socio-cultural meaning. The International Journal of Language, Society and Culture, 21, 1-8. 